\title{
SmartEnCity
}

\section{EUROPEAN UNION HORIZON 2020 SMART CITY APPROACH AND ITS APPLICATION IN THE BULGARIAN CONTEXT}

\author{
Mrs. Ivanka Pandelieva-Dimova \\ Sofia Energy Centre, Bulgaria
}

\begin{abstract}
Urban sustainability is a major pillar in the European Union policy towards reaching Paris Agreement targets. In order to support cities and local communities around EU in their effort to implement innovative solutions and integrated approaches to increase their resource efficiency and climate resilience, European Commission funds the instrument "Smart Cities and Communities" (SCC) as part of its Research and Innovation Programme Horizon 2020 (H2020). The overall approach is to define and implement sets of innovative integrated sustainable actions in three main domains: energy, urban mobility and information and communication technologies at city/municipal level. The most innovative solutions are implemented by a number of lighthouse cities while follower cities closely observe the actions being performed in the lighthouse cities, and commit to select and put into practice the most promising and adaptable ones depending on their local conditions. Since 2015 four Bulgarian cities have been part of SCC projects, namely Sofia, Bourgas, Varna and Asenovgrad, participating as followers and working together with local communities from all across Europe leading the way towards urban sustainability and carbon emission reductions. Asenovgrad is supported by Sofia Energy Centre as partner in Horizon 2020 SmartEnCity Project where it cooperates with the lighthouse examples of VictoriaGasteiz (Basque Country, Span), Tartu (Estonia) and Sonderborg (Denmark) on their path to achieve carbon neutrality in the long-term perspective.

The article presents the overall H2020 SCC approach based on the implementation of most advanced processes, materials and products applicable to different areas of urban sustainability. Taking the experience of SmartEnCity lighthouse cities as a starting point, it is focused on the ways to successfully adapt the most promising solutions matching the specific Bulgarian conditions. In addition, on-going cooperation among Bulgarian follower cities has been initiated which helps in broadening the scope of possible measures and utilization of available knowledge beyond the project boundaries.
\end{abstract}

Keywords: EU funding, smart cities and communities, holistic approach, sustainability, lighthouse 


\section{INTRODUCTION}

Urban areas are in at the centre of EU policies for low-carbon and resource efficient economy given the fact that more than $70 \%$ of population lives in cities consuming 70 $\%$ of energy.[1] In order to support cities and local communities to increase urban sustainability and achieve smart and environmentally friendly economic growth, European Commission has created the instrument "Smart Cities and Communities" (SCC) as part of its Research and Innovation Programme Horizon 2020 (H2020). The instrument focuses on urban solutions at the intersection of energy, urban mobility and information and communication technologies (ICT). The measures in these areas have been viewed as a complex, taken in their mutual dependency and internal relations thus enabling gradual transition into smart and sustainable cities. Major element in this concept is the innovative part of the proposed measures which should bring significant economic, social and environmental benefits, and lead to better quality of life.

Cost effective and resource-efficient integration of open, resilient and adaptable technologies in urban environments is not a straightforward task; it involves linking different technologies and addressing issues of diverse nature. This complex scenario has been analysed and described by European Innovation Partnership (EIP) on Smart Cities and Communities. Figure 1 provides a graphic overview of the three main pillars that have been identified (Sustainable urban mobility, Sustainable districts \& built environment, and Integrated infrastructure \& processes), and the relevant horizontal aspects that are addressed in an effort to streamline implementation and mitigate associated risks.

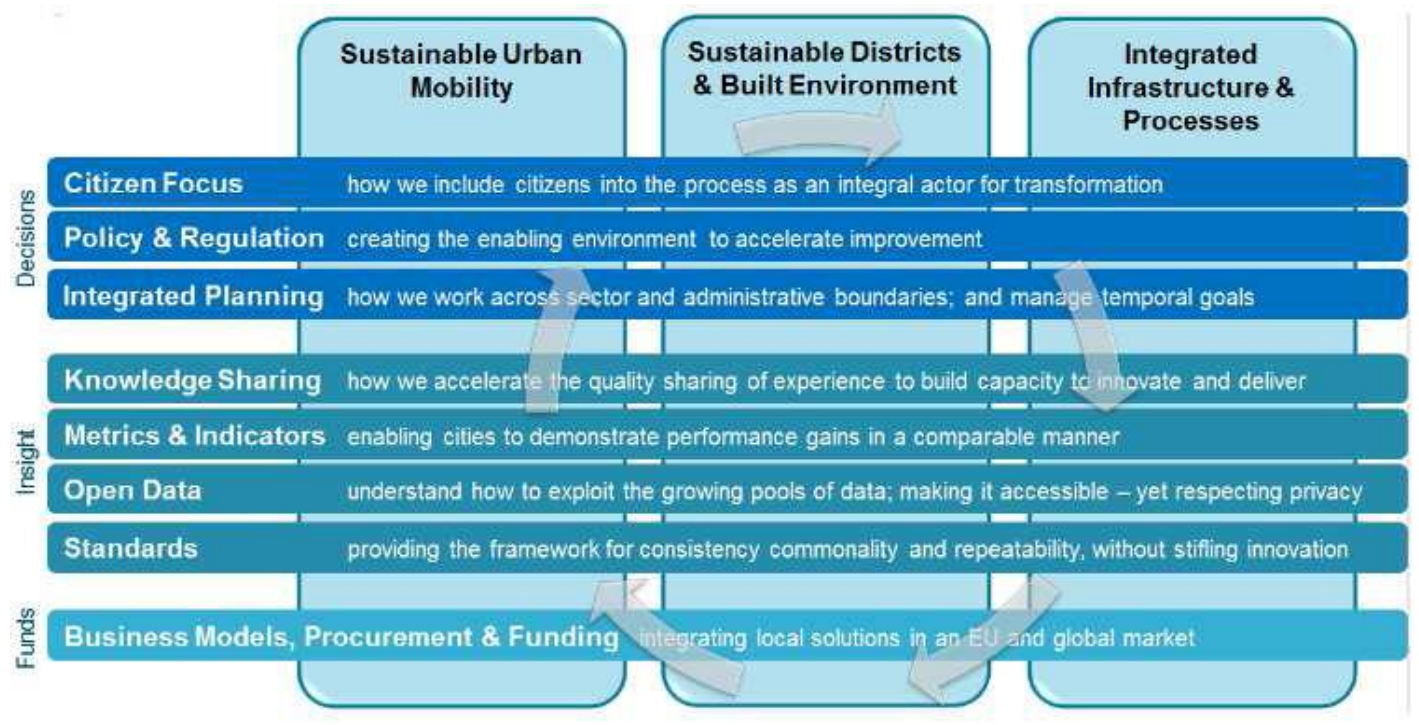

Figure 1: EIP Strategic Implementation Plan Priority Areas

Following the above priorities, Smart Cities and Communities (SCC) projects have been implemented all across Europe (SSC1) aiming at demonstration of sustainable, costeffective and replicable district-scale solutions based on the presented holistic approach involving energy, urban mobility and ICT. SCC projects bring together cities and local communities with industries, research institutions, technology providers, and citizens, and realize actions that lead to measurable results in increase of resource and energy efficiency, and in creation of new markets and new jobs. These actions include, among 
others, building stock refurbishment to nearly zero energy standards, provision of secure, affordable and clean energy through high shares of renewables, introduction of electro mobility, smart energy grids, energy storage, electric vehicles and smart charging infrastructures, larger use of (ICT) in buildings, transport and services. Particular innovative solutions are being implemented in a number of lighthouse cities and should clearly demonstrate replicability and potential to be scaled-up in other urban areas. The follower cities play special role in this project concept; they should review the solutions applied in lighthouse cities and commit to implement those which are most suitable for their local conditions.

\section{SMARTENCITY PROJECT}

\section{Concept}

SmartEnCity's aims to develop a scalable holistic approach for transformation of European cities into sustainable, smart and resource-efficient urban areas through the integrated planning and application of measures for energy efficiency, increase of renewable energy supply and sustainable urban transport, supported by appropriate ICT solutions. It started in 2016 and runs for five and a half years involving thirty five partners from all over Europe among which city administrations, home owners associations, research institutions, technology providers, consultancy organizations. Participating partners from Bulgaria are Asenovgrad Municipality and Sofia Energy Centre as its supporting and consulting organization.

The underlying concept of the project is the Smart Zero Carbon City (SZCC) concept, where city carbon footprint and energy demand are kept to a minimum through the use of demand control technologies that save energy and promote raised awareness; energy supply is entirely renewable and clean; and local energy resources are intelligently managed by aware citizens, as well as coordinated public and private stakeholders.[2] This approach is being applied in the three Lighthouse demonstrators: Vitoria- Gasteiz in Spain, Tartu in Estonia and Sonderborg in Denmark where a number of specific actions are being implemented in following three main areas:

\section{Low energy districts:}

a. Energy retrofitting of buildings: elaboration of a context-adaptable systemic approach towards significant reductions in the energy consumption of the building stock, addressing the key technology issues as well as identified financial and social barriers, and making use of the energy reduction potential of ICT;

b. District heating networks: cost effective implementation scenarios, significant increases in renewable share, efficiency improvements linked to intelligent control technologies, and residual energy recovery and use;

c. RES integration and management: identification and use of not realized potential in RES, as well as intelligent management of electric urban infrastructure.

2. Sustainable Mobility: a number of measures dealing with clean energy source promotion in both public and private fleets, as well as intelligent management for improved efficiency, optimized operation, and better integration of clean transport modes in the developing urban scenarios. 
3. Information and Communication Technologies (ICTs) considered as cross-cutting, enabling technologies that will be used for monitoring and evaluation of the success of measures, as well as a means for management, control and integration of valuable information provided and made accessible to different stakeholders and a tool for social interaction.

These actions are to be aligned to city-specific Integrated Urban Plans (IUPs) of the lighthouse cities, and the process will be replicated in two follower cities, Lecce, (Italy), and Asenovgrad (Bulgaria), to ensure adaptability and maximize the project impact. Additionally, a Smart Cities Network has been setup to support project replication at European scale.

A specific feature of SmartEnCity differentiating it from the rest of SCC projects is that it focuses on small and medium-sized cities which often play a pivotal role within regional economies. As stated in DG Regio's report "they are essential for avoiding rural depopulation and urban drift, and are indispensable for the balanced regional development, cohesion and sustainability of the European territory".[3] Reflecting on the importance of smaller urban communities for the overall European development, the participating cities (both lighthouse and followers) are medium to small sized cities in Europe, sharing a solid background and capable to offer lessons from outstanding accomplishment in specific areas linked to the scope of the SmartEnCity project. The figure below maps the geographical dimension of the project:

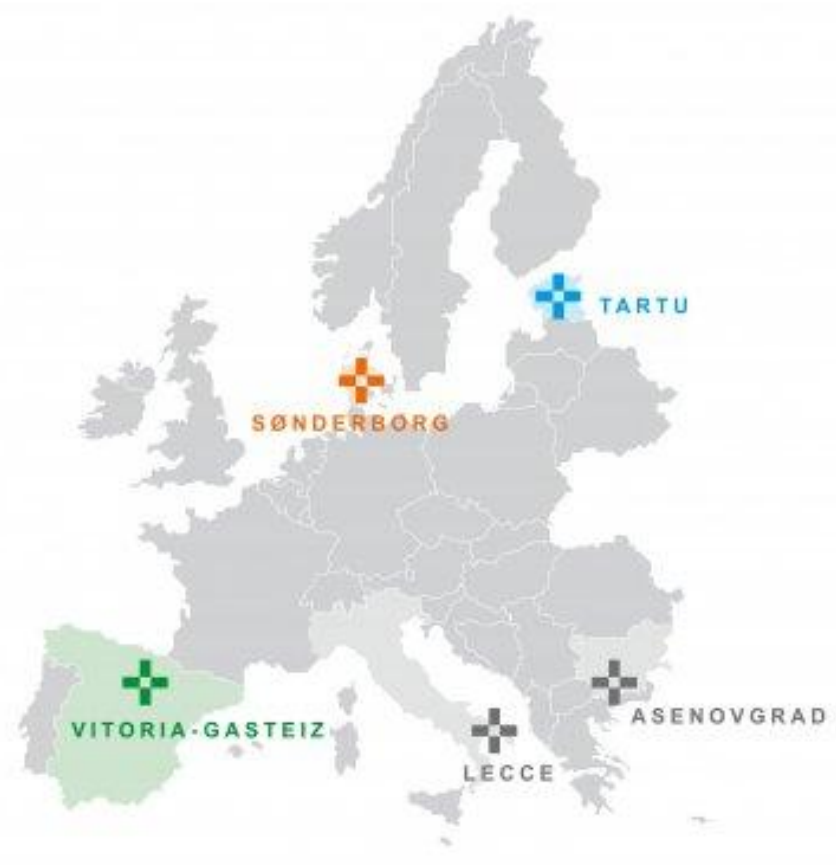

Figure 2: Map of SmartEnCity Project

\section{Objectives and expected results}

\section{Technical objectives:}

$\checkmark$ Developing a methodology to guide the evolution process of urban areas towards smart cities through the SZCC Strategy. 
$\checkmark$ Demonstrating how current available technologies pave the way for the SZCC concept.

$\checkmark$ Holistic evaluation of the complex of measures in the three lighthouse cities and the possibility for replication in the follower cities.

\section{Replication objectives:}

$\checkmark$ Developing Integrated Urban Plans in the lighthouse and follower cities.

$\checkmark$ Definition of innovative business models.

$\checkmark$ Developing communication and dissemination actions to pave the way for future replication strategies.

\section{Social objectives:}

$\checkmark$ Involving citizens in district renovation processes.

$\checkmark$ Creating labour opportunities for the most vulnerable social sectors.

Involving citizens in the transformation processes towards urban sustainability is viewed as especially important aspect of SmartEnCity project as the ultimate goal of every action taken at city level is the well being and increased quality of life of its inhabitants. Citizens therefore, must play pro-active role in defining the strategic goals and visions adopted by the city administration. Following is a visualization of citizen engagement approach adopted by the project.

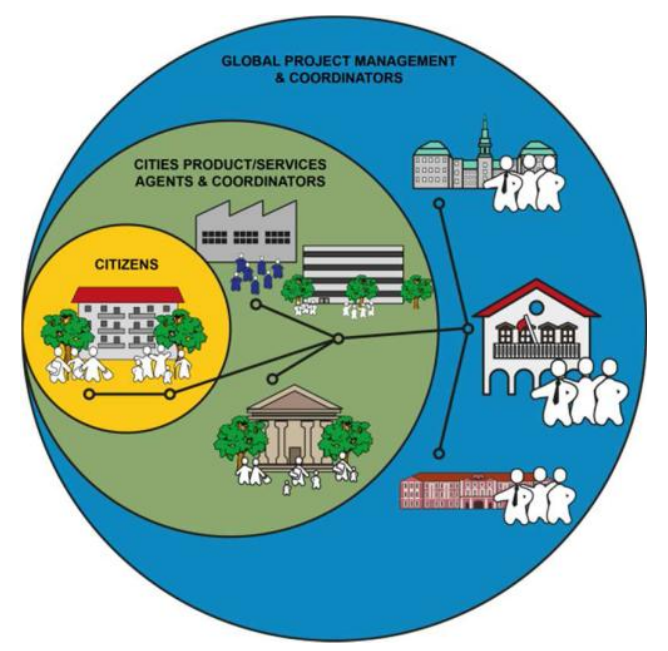

Figure 3: SmartEnCity Citizen focused approach

The above stated objectives are currently being achieved through the implementation of an integrated set of measures in Vitoria-Gasteiz, Tartu, and Sonderborg, intending to be replicated in the follower cities of Lecce and Asenovgrad, as well as in the cities part of the SmartEnCity network. After successful completion of the project it is expected to have the following main results:

- Retrofitting of about 2500 dwellings and over $165,000 \mathrm{~m}^{2}$;

- Benefits for 29300 inhabitants;

- Energy savings of about 30,000,000 kWh/y;

- $\mathrm{CO}_{2}$ reduction of $19000 \mathrm{Tn} / \mathrm{y}$; 
- Increased use of renewable energy sources for heating;

- Smart lighting concepts;

- Innovative strategies for sustainable mobility (electric vehicles, bike and car sharing, biogas buses etc.).

\section{SMARTENCITY ACTIVITIES IN ASENOVGRAD, BULGARIA}

As one of the follower cities in the project, the main role of Asenovgrad is to adapt its existing Integrated Plan for Urban Regeneration and Development (IPURD) and create the associated roadmap that will guide the SmartEnCity replication. It is important to note that Asenovgrad is the only city in the project which has already developed its urban plan IPURD which is already in the implementation phase. SmartEnCity activities provide an excellent opportunity for Asenovgrad local administration to review and update the planned measures, and align them with the smart city concept at the same time enlarging the horizon of the cities vision for sustainable, efficient and climate neutral development.

Asenovgrad Municipality features favourable conditions to be part of SmartEnCity project. It is a mid-sized municipality with approximately 68000 inhabitants situated at the foot of Rhodope Mountains. The geographic location of the municipality and its climate provide potential for renewable biomass utilisation for energy production. There are significant water resources leading to the installation of hydro power plants and studies show also potential for solar and wind energy. The energy infrastructure includes electricity and gas distribution networks while space heating is done through local/individual heating systems. The main policy priorities of Asenovgrad Municipality are: development of economy, human resources and infrastructure, and environmental protection.

Asenovgrad has a long tradition in sustainable energy policies and actions being a signatory of Covenant of Mayors and its Sustainable Energy Action Plan (SEAP) has been already approved and is being monitored. The main priority areas of the SEAP are: reduction of energy consumption in buildings through building refurbishment; street lighting refurbishment; energy efficiency in public transport and deployment of electric vehicles, energy efficiency in local industries; utilization of available renewable energy potential including shift from heavy fuel oil to biomass; introducing energy management systems. As already stated, Asenovgrad has developed its IPURD and one of the main tasks within SmartEnCity is to update the plan with more ambitious targets with longer time horizon (up to 2030 and beyond), and to develop a road-map with concrete projects to be implemented according the potential for interventions in the identified zones.

Thus the main role of Municipality of Asenovgrad in the SmartEnCity context is to build on its already existing policy documents, identified potential and priority areas by modifying and enriching them with lighthouse cities' experience gained through the project. Asenovgrad is committed to exploitation and replication of successful business models developed within the lighthouse cities that best fit its local conditions. In addition the municipality has the ambition to achieve a high level of environmental protection through legally regulated, environmentally clean and efficient waste management. 
According to the IPURD, Asenovgrad's vision for the development until 2020 is: a town with thousand years of history with preserved spirit and past values but open for the future challenges; an attractive place for business and life. Following this vision, there are a number of strategic goals defined:

$\checkmark$ To be an attractive place for business and tourism;

$\checkmark$ To provide better quality of life in the urban environment while preserving and underlining the cultural identity;

$\checkmark$ To be energy efficient and environmentally friendly development;

$\checkmark$ To ensure more effective government and stakeholder collaboration

In order to achieve the above goals, several priorities have been formulated, as follows:

$\checkmark$ Priority 1: Preserving the authenticity and increasing the attractiveness and functionality of urban spaces;

$\checkmark$ Priority 2: Developing a competitive and dynamic local economy providing for realization of human resource potential;

$\checkmark$ Priority 3: Improving public services;

$\checkmark$ Priority 4: Improvement of living standard.

There is also an implementation plan for IPUDR of Asenovgrad which consists of detailed list of projects, necessary funding and potential investment sources. Part of this plan has already been realized resulting in 22 multi-family residential buildings already refurbished and additionally 28 contracts signed with total investment of over 12 MEuro. Other performed measures include: 9 schools and kindergartens refurbished with total investment of 2,1 MEuro; two electric vehicles for municipal fleet purchased; waste water treatment plant have been constructed with total investment of 11 MEuro.

In the process of IPURD a number of challenges have been encountered among which insufficient administrative capacity at the municipality; insufficient citizen engagement, difficulties in monitoring and data collection to verify progress, and others. It has been concluded that in order to enhance the implementation of foreseen measures there are different needs to be fulfilled especially applicable to citizen engagement activities and ensuring better cooperation with local energy utilities (electricity and gas distribution companies).

\section{COLLABORATION WITH OTHER BULGARIAN FOLLOWER CITIES}

During SCC projects implementation, special focus has been put by the European Commission on providing better opportunities for adoption of the successfully demonstrated approaches and solutions. For this purpose collaboration among different SCC initiatives has been initiated allowing participating cities to benefit not only from the results achieved within their own consortium but also from the entire "family" of running lighthouse projects which broadens the scope of possible answers and enlarges the opportunities to spot solutions which mostly match the specific city needs. As the problems faced by the cities usually have strong local component, of special interest for Asenovgrad are the other SCC activities featuring Bulgarian participation. Thus a tradition have been established for cooperation and mutual contributions among the four Bulgarian follower cities - Sofia, Bourgas, Varna and Asenovgrad. In the framework of this cooperation a number of joint events have been organized on different Bulgarian 
locations: in Sofia on 12 July 2017, in Bourgas on 30 August 2017 and in Asenovgrad on 15 March 2018. During these joint events the Bulgarian follower cities presented their activities and discussed the common challenges that need to be addressed and barriers to overcome in order to continue the transformation to smart and sustainable urban communities. This tradition proved successful and beneficial for the Bulgarian follower cities and the next joint event is planned to be held in Bourgas in September 2018.

\section{CONCLUSION}

The transition of cities towards a low carbon and resource efficient economy, through planning and implementation of integrated measures in the energy, transport and ICT sectors is a key element for achieving the strategic policy goals of European Union for 2030 and 2050, and meeting the targets of Paris Agreement. On the other hand, one of the main future challenges for European cities lies in the adaptation of their urban environments to accommodate more sustainable and inclusive societies that improve citizens' quality of life, create jobs and wealth, and offer growth opportunities in equality.

In this context, projects for facilitating city investments in integrated innovative technologies servicing buildings, heating and cooling, mobility, lighting and ICT are seen as key elements in the transformation process towards more resource efficient, economically viable and socially cohesive environments. So far there have been four calls for SCC proposals resulting in 36 lighthouse cities and 42 follower cities participating in SCC projects [4] and this number has been growing. Thus there are continuous funding opportunities provided by Euroepan Union's Horizon 2020 Programme with the aim to take on board more and more cities willing to become smart and sustainable urban environments.

Another important aspect is the high replicability potential of these projects and the opportunities of other cities and communities to learn from the experience of lighthouse projects and adapt the tested solutions to their local conditions. The role of SmartEnCity Network in this respect is significant and all interested stakeholders across Europe are invited to join the network and benefit from the experiences and lessons learnt in the process of SmartEnCity project implementation.

\section{REFERENCES}

[1] HORIZON 2020 - Work Programme 2016 - 2017, Cross-cutting activities (Focus Areas), page 105;

[2] SmartEnCity - Towards Smart Zero CO2 Cities across Europe, http://smartencity.eu/about/, 2016;

[3] European Union Regional Policy "Cities of tomorrow. Challenges, visions, ways forward”, Executive Summary, page VII, October 2011;

[4] Jens Bartholmes, UNIT C2, European Commission - DG ENERGY, Horizon2020

Programme for Research\&Innovation 2018-2020, Smart Cities and Communities SCC1

- 2018, presentation at SCC Information Day in Brussels, Belgium, 24 October 2017, https://ec.europa.eu/easme/sites/easme-site/files/02_20171024__bartholmes_sccl_info_day_-jb.pdf 